\title{
ECONOMIC DEVELOPMENT BY THE CREATION OF NEW SECTORS
}

\author{
P.P. Saviotti, INRA, Université Pierre Mendès-France, BP 47, 38040 Grenoble Cedex 9, \\ France. Tel: +33 4 76825831; Fax: +33 4 76825455; E-mail: saviotti@ grenoble.inra.fr; \\ and IDEFI, CNRS, Sophia Antipolis, Tel: +33/0 4939541 52, Fax: +33/0 493653798
}

\author{
A. Pyka, Economics Department, University of Augsburg, Economics Department, \\ Universitätsstr. 16, D-86135 Augsburg, Germany. andreas.pyka@ wiwi.uni-augsburg.de \\ Tel: +49/821-598-4178, Fax: +49/821-598-4229
}

\begin{abstract}
APRIL 2002
\section{1) INTRODUCTION.}

For many countries economic development has created an enormous amount of wealth increasing the welfare of most members of their populations. In many growth models the representation of economic development underlying formal modelling exercises assumed that technical progress would in the course of time increase the productivity of all existing processes, thus leading to the possibility of a greater output per unit of resources employed in production. Economic growth would arise because more final goods would thus be available for each member of the population. Even the most causal observation tells us that this representation does not correspond to what happened in one important respect. Both the types of output ad the activities used to produce them are qualitatively different from those that were previously used in the economy. We can thus say that the composition of the economic system changed during economic development. Here by composition we mean the list of all objects (products or services), activities and actors (individual ad institutional) that are required to describe the economic system at a given time. Furthermore, qualitative change necessarily entails structural change, although the two phenomena are not identical. Structural change only results from the emergence of new sectors, from the extinction of old ones, and from the changing weights of surviving sectors. Qualitative change can occur at lower levels of aggregation, for example in the internal composition of a sector or even in that of the technical objects or of the activities within each sector. The two phenomena are, however, closely related.
\end{abstract}

The importance of the previous considerations changes drastically depending on whether qualitative change is only an effect of previous economic development or also a determinant of subsequent economic development. In the latter case changes in the composition of the economic system should become one of the important variables in models of economic growth and development. Our knowledge of the relationship between economic development and qualitative change is very limited. This paper attempts to shed light on some important aspects of the role played by qualitative change in economic development, by laying the foundations of a model in which changes in the composition of the economic system are endogenously generated by the evolution of the system itself and, in turn, affect its future development. To put it in another, slightly different, form, we can say that economic development is a process in which new activities emerge, old ones disappear, the weight of all economic activities and their patterns of interaction change. 
Most existing models of growth are macroeconomic models. Thus they do not take the composition of the economic system into account. This does not mean that it is impossible for any macroeconomic growth model to derive some of the implications of changing composition. However, it means that this possibility is limited. For example, in Romer's models $(1987,1990)$ one of the outcomes of $R \& D$ activities is to increase the number of sectors producing capital goods. Obviously, this amounts to a change in the composition of the economic system. In Aghion and Howitt's (1998) multisectoral extension of their endogenous growth model the existence of several sectors producing intermediate outputs and of their interactions are examined. However, the number of sectors does not change in the course of time. In general, in these models there is no indication of what the new capital goods could be or of their potential interactions with the consumer goods sectors. In fact consumer goods and services are the really missing character from all these models. This is probably due to the use of production functions that, while admitting many inputs, can produce only one output. In particular, the implications of these models for the variety of the economic system are unclear. In Romer's models we can expect variety to increase, although we do not know under what circumstances and in what directions. In Aghion and Howitt's models variety is likely to remain constant. Thus we can see here that endogenous growth models, while being an important improvement with respect to the Solow-Swann vintage, still have difficulties in coping with the dynamics of qualitative change taking place in the economy. Macroeconomic growth models are useful precisely because they do away with all, or some of the complexities inherent in the composition of the economic system. The simplification that they achieve in this way helps these models to achieve in a parsimonious and elegant way some important results, but limit their ability to deal with the composition of the economic system. Of course, such limitation is much more serious in the long than in the medium or short run, since changes in composition affect the macroeconomic level rather slowly. Thus, the more profound limitation of macroeconomic growth models is likely to be their ability to analyse long term trends in economic development.

Another type of research relevant for the purposes of the present paper is that on structural change. Important examples of this research are the work by Salter (1960), by Cornwall (1977), and more recently by Fagerberg (2000) and by Fagerberg and Verspagen (1999). These works are mostly empirical, but an important attempt to formulate a theoretical model linking structural change and economic growth was made by Pasinetti $(1981,1993)$. The work of all these authors takes structural change into explicit account and they provide an important inspiration for our work. However, this past work on structural change still leads to a number of problems, at least some of which we aim at overcoming. First, the definition of structural change used by the previously quoted authors refers to the emergence of new sectors, to the disappearance of older ones and to their changing weights in the economic system. Aspects of qualitative change taking place at a lower level of aggregation, although having impacts at the sectoral level, are not taken into account. In this paper the term qualitative change refers to a wider range of changes in the composition of the economic system. This aspect will be clarified in the subsequent discussion of variety. Second, the possibility to detect structural change and to study its effects depends heavily on the availability of statistical data about production and above all on the definition of industrial sectors used. Statistical classifications of production are changed infrequently and in ways that do not necessarily reflect the real changes taking place in the economy. Thus, as it emerges clearly from the work of Fagerberg and Verspagen $(1999,2000)$ the industrial classification that they have to use in order to compare a large number of countries hides some types of structural change. Third, these studies on structural change have remained somewhat separate with respect to the 
macroeconomic growth models. Fourth, even the most sophisticated model linking structural change and economic growth, that of Pasinetti, has very limited dynamic features: it leads us to the conclusion that in the long run the economic system cannot follow a balanced growth path unless new sectors emerge and 'absorb' the resources potentially displaced by the evolution of older sectors, but it does not tell us anything about the dynamics of emergence of new sectors or about their relationship to older ones. Our paper aims at laying the foundations for a model of economic development that includes qualitative change amongst its main determinants. Thus we hope to contribute to a better understanding of the role of qualitative change and to bridge the gap between macroeconomic growth models and structural change studies. In what follows the conceptual nature of the present model will be explained, followed by the presentation of the more technical aspects of the model and by its results.

\section{2) THE CONCEPTUAL NATURE OF THE MODEL.}

In this paper an industrial sector is represented by a population of firms producing a differentiated good or service. Firms within the population differ for the characteristics of the goods/services produced. Firms within each population perform search activities as a result of which the quality of their goods or services improve and their production becomes more efficient. In the framework of this paper we can imagine economic development to begin with a number of 'given' sectors, that is sectors producing goods or services that have always existed. Such goods and services were known to consumers, although their quality or efficiency of production could increase during economic development. Other sectors were subsequently created by innovations that were sufficiently radical in order for the corresponding goods or services not to be imagined by consumers. The result of any such innovation is to create a potential market which, however, is initially empty because there is no production capacity for the goods or services defining the market. Here automobile, the aircraft and the computer are examples of innovations that established completely new markets. At the time of their invention these markets were completely empty. This situation is formally represented in our model by saying that an innovation creates an adjustment gap, equal to the difference between the maximum possible demand that could be envisaged at time zero of the good/service lifecycle $\left(D_{i, \max }\right)$ and the actual demand at the same time $\left(\mathrm{D}_{\mathrm{i}}\right)$. The adjustment gap at a given time thus represents the part of the market demand that cannot be satisfied by the existing production capacity. Alternatively the adjustment gap can be imagined as the distance of the sector from saturation. We expect the rate of growth of the number of firms in a sector to be proportional to the adjustment gap $\left(D_{i, m a x}-D_{i}\right)$.

The maximum demand for a given type of good/service $\left(D_{i, \text { max }}\right)$ does not necessarily remain constant in the course of time. We expect that in general $\mathrm{D}_{\mathrm{i}, \mathrm{max}}$ will increase as a result of search activities leading to an increased quality and to a falling price of the given good/service. Computers are perhaps the most spectacular if not the most representative example of such an improvement. If computers had remained what they were in the early 1950s their diffusion would have been severely limited by their extremely high price. Furthermore, the improvements in their performance that took place in the following period greatly increased the number of their potential applications thus expanding the number and size of markets in which they could be sold. Although computers cannot necessarily be considered representative of other technologies, since their rate of growth of productivity is an order of magnitude higher, the two types of change described above are common to the evolution of any innovation which is significant enough to create a new sector. On the one hand the increasing efficiency of production reduces the price of the innovation, thus increasing the number of adopters for a given type of use. On the other hand changes in the 
services performed by the innovation increase the number of markets or sub-markets in which it can be sold. It is to be remarked that, according to these considerations, the so called new economy would differ from any previous important innovation, such as the railways or the automobile, only because its rate of productivity growth is much higher. The model described in this paper is in principle applicable to all the important innovations that arose from the time of the industrial revolution.

Both cost reducing and service expanding developments can expand the population of potential adopters of the given good/service. Our conception of the adjustment gap is here very similar to that of Metcalfe (1981) in his diffusion model. We expect the adjustment gap to fall during the life cycle of the sector as new entrants raise the sectoral production capacity. However, we do not expect it to fall at all times. It is quite conceivable that during certain periods $D_{i, \text { max }}$ can increase more rapidly than $D_{i}$, due to technical progress or to increasing returns to adoption. In the end we expect decreasing returns to set in and the adjustment gap to fall gradually to zero or to a very low value as the sector becomes saturated. Thus, the expected time path of the adjustment gap depends on the relative rates of change of $D_{i, \max }$ and of $D_{i}$. Furthermore, the adjustment gap is related to the level of search activities performed, to the fitness of the technology used and to the volume of the product population in service characteristics space.

Search activities are here defined as those activities by means of which firms scan the external environment looking either for alternatives to their present routines or for completely new opportunities. R\&D is the most common but not the only example of search activities. Their common defining feature is to be forms of learning by not doing (Saviotti, 1998). Search activities help us reduce the cost of large scale trial and error experiments by scanning the external environment and pointing both to fruitful and to fruitless experiments. The fitness of a given technology can be defined as the capacity to adapt to its external environment (Saviotti, 1996). This definition of fitness is very general but difficult to apply. Thus an approximate but more easily applicable definition is the ratio of the services performed by a given technology to its price. Here it is to be stressed that in this paper we are mostly concerned with product technology. Thus we now proceed to describe briefly a characteristics representation of product technology, on which the concept of population of firms is based.

\section{1) A CHARACTERISTICS REPRESENTATION OF PRODUCT TECHNOLOGY.}

The goods or services produced by firms can be represented by means of two sets of characteristics corresponding to the internal structure of a given product technology and to the services performed for its users respectively (Saviotti, Metcalfe, 1984; Saviotti, 1996). The two types of characteristics are called technical and service characteristics respectively (Fig. $1)$.

$$
\left(\mathrm{X}_{\mathrm{i}}\right) \Leftrightarrow\left(\mathrm{Y}_{\mathrm{j}}\right)
$$

Fig 1. The twin characteristics representation of product technology. The $X_{i}$ 's are the technical characteristics and the $\mathrm{Y}_{\mathrm{j}}$ 's are the service characteristics.

The double arrow in Fig. 1 between the two sets of characteristics means that they are not independent, but that there is a correspondence between the two sets. In fact, service characteristics cannot be produced 'directly', but they are provided by embodying in the products certain technical characteristics that lead to the desired services. Each firm produces a set of differentiated product models, each model being represented by a point in 
characteristics space. The collection of the product models produced by all the firms in an industry constitutes what can be alternatively called a product population or a technological population. The two expressions are here equivalent since in this paper we are concerned with product technology. Thus a technology/product population coincide with an industrial sector. Graphically such a population can be represented by the distribution of points/models in characteristics space. The distribution takes the form of a cloud, either ellipsoidal or more structured. The volume of the cloud corresponds to the extent of differentiation of a given population. We expect a greater extent of differentiation to lead to a larger market at given time. In this approach the collection of firms producing a differentiated product corresponds to an industrial sector. Different industrial sectors can be found in the same or in completely different dimensions of characteristics space (Fig. 2).

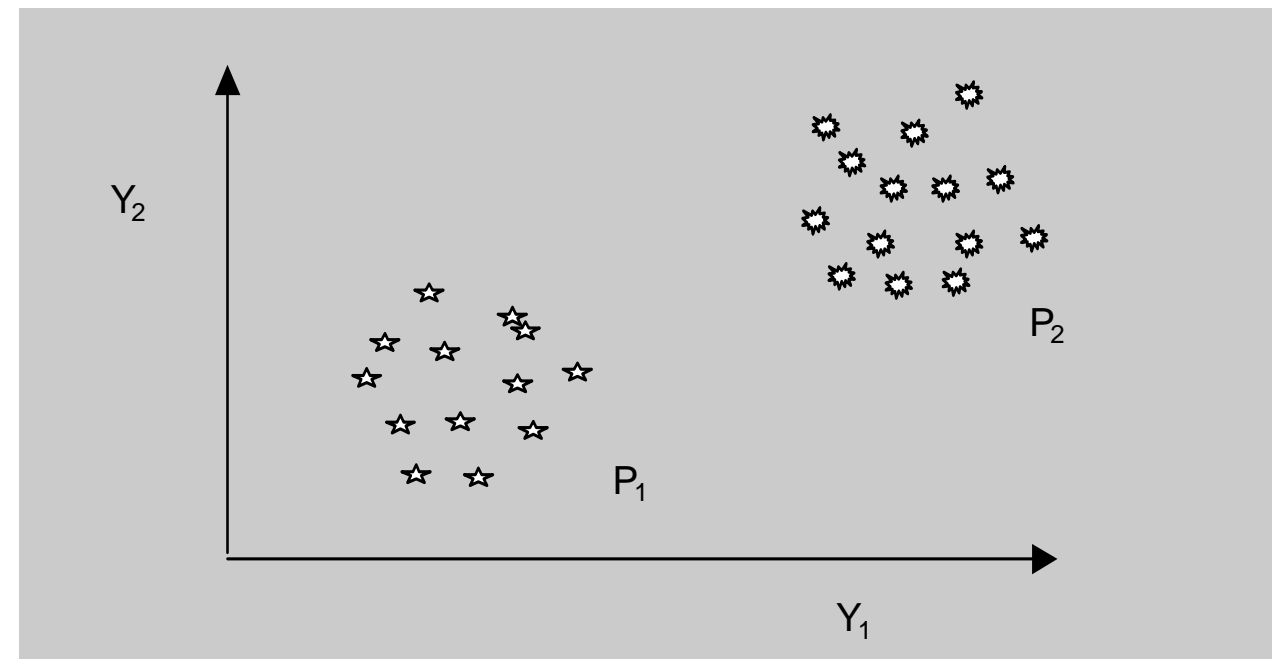

Fig. 2. Examples of two technological/product populations in the same dimensions, $\mathrm{Y}_{1}$ and $\mathrm{Y}_{2}$, of characteristics space.

Populations $t_{1}$ and $t_{2}$ represent two industrial sectors in the same dimensions of characteristics space, $Y_{1}$ and $Y_{2}$. Sectors belonging to completely different dimensions of characteristics space cannot be represented graphically because at least four dimension are required. It is to be stressed that this definition of industrial sectors does not correspond to the one used in industrial statistics. Currently used definitions are far more empirical than the one used in this paper . Furthermore, the aggregation procedures used in industrial statistics often combine goods and services that according to our approach should not be related. Thus the definition of industrial sectors used in this paper is conceptually more rigorous but it is not easily compatible with the one currently adopted in industrial statistics. However, our approach is suitable for the goals of this paper in which we are concerned with the basic features of a model where the emergence of new industrial sectors, leading to qualitative change, is a fundamental component of economic development.

From the previous analysis it follows that the volume of the cloud of points representing an industrial sector is a measure of the extent of its differentiation. Both the fitness of the technology and the volume of the population in characteristics space can be expected to increase in the course of time as a result of search activities. Thus we can expect:

$$
D_{i, \max } \propto S E_{i} \propto F_{i} \cdot V\left(Y_{i}\right)
$$


The reason for which $D_{i, \max }$ is expected to be proportional to the product of $F_{i}$ and of $V\left(Y_{i}\right)$ is that we can expect a new sector to be created starting from a niche, where $F_{i}$ will be high, although the niche is likely to be very small. In the course of time both $F_{i}$ and $V\left(Y_{i}\right)$ will increase. Thus we can expect the maximum demand to be proportional to the product of the two.

There will be entry (or birth ) and exit (or death) into and from each population. Here entry is determined by the size of the adjustment gap and by financial availability. Exit on the other hand is determined by the intensity of competition and by mergers and acquisitions. In order to explain these mechanisms we have here to deal with the concept of competition used in this paper.

\section{2) Competition.}

The concept of competition present in this paper differs somewhat from the one generally used. First similarly to the concept of competition used in biology (Maynard Smith, 1974), firms are assumed to compete for a resource which is present in scarce supply. Second, firms are assumed to compete by being different, by attempting to create something that other firms cannot match, not by trying to do the same thing that other firms do more efficiently. Of course, considerations of efficiency cannot be excluded, but what matters is that the attempt to differentiate themselves with respect to other firms is an important component of the competitive strategy of firms. According to Metcalfe and Gibbons (1991) this type of competition can be called Schumpeterian, as opposed to the classical, perfect like competition. Furthermore, the concept of competition used here has something in common with Hayek's (1978) concept of competition as a discovery procedure (For a more extended discussion of this point see Saviotti, Krafft, 2002). Analytically this implies that the intensity of competition cannot be measured simply by the number of competitors. Two industrial sectors having the same number of firms can have different intensities of competition depending on the density of product models in their population and on the presence of competition with other industrial sectors.

As pointed out above a population of firms producing a differentiated product and corresponding to an industrial sector, is represented by a cloud of points/models in a multidimensional characteristics space. A population occupies a self-contained region of characteristics space which can be clearly demarcated from the regions of characteristics space containing other populations, corresponding to different sectors. Even within the same population product models compete depending on their similarity: very close by and therefore, very similar, product models, compete very intensely, while very far apart and very different models have a very low intensity of competition. Yet, however far apart different product models are, their intensity of competition is not necessarily zero. As far as a particular product population is concerned, a greater density of models, corresponding to a lower average distance, leads to a higher intensity of competition. The density of a particular product population is an additional variable required to measure the intensity of intrapopulation competition. However, this type of competition is not the only one to be taken into account. Two populations can be different if the respective product technologies are different, in the sense that they are represented by different characteristics. Yet, in spite of having different internal structures, and thus of belonging to different populations, two product technologies can have some service characteristics in common. For example, trains, aircraft, buses and cars are distinguishable transport technologies: their internal structures are clearly 
different. Yet they all supply comparable, though not identical, transport services. Thus they are competing, at least in some sub-set of the market for transport services. This example is by no means unique. E-mail and fax, cinema and television, are just some other examples of pairs of product technologies having different internal structures but supplying comparable services. The general conclusion is that competition does not come only from within the same sector, but also from other sectors. The two components previously described can be called intra- and inter- population (or intra- and inter-industry) competition respectively. This distinction is very important in order to appreciate the concept of competition used in this paper. Traditionally a monopolist was considered to produce a $100 \%$ of the output of a given sector. With the concept of competition used here a monopolist would only be free of competition if there was no inter-population competition. It can easily be realised that the intensity of inter-population competition is at least an important component of market contestability.

The intensity of competition within a given population or sector represents also the extent of product differentiation within the population. We can understand this if we imagine to perform a simple mental experiment. Starting from a given population constituted by a cloud of points, we can imagine to collapse it into a point. In this way we would have eliminated all the differentiation of the product models contained in the population. In other words, we would have gone back to the case of homogeneous and identical products assumed in perfect competition. If we now imagine to reverse the process and to start differentiating the population from the single point to which we had reduced it, we can realise that the density of the population can be expected to decrease as it becomes more differentiated. We can then see that this representation of competition encompasses all the situations from perfect competition to monopolistic competition.

We can summarise the previous discussion by saying that to measure the intensity of competition we need to take into account both inter- and intra- population competition. Also, according to the previous considerations we expect intra-population competition to be proportional to the density of models in service characteristics space:

$$
I C_{i}=f\left(N_{i}, \rho_{i}, 1 / D_{y}(i, j)\right)
$$

Where $\mathrm{IC}_{\mathrm{i}}$ is the overall intensity of competition in population $\mathrm{i}, \rho_{\mathrm{i}}$ is the density of models in population $i$, constituting a measure of intra-population intensity of competition, $D_{y}(i, j)$ is the average distance in service characteristics space between population $i$ and other populations $j$ providing comparable services, constituting a measure of inter-population intensity of competition.

The intensity of competition is determined only by service characteristics because only these characteristics determine directly consumer demand. Thus it is in principle possible for the technical characteristics of a sector to show a greater degree of dispersion than the corresponding service characteristics, due to the possibility of achieving similar service characteristics levels starting from different technical characteristics.

The intensity of competition plays a very important role in our model. We expect that as a new population is created by an entrepreneur developing a radical innovation, the intensity of competition will initially be very low, corresponding to the temporary monopoly enjoyed by a Schumpeterian entrepreneur. If the innovation is successful imitation and entry will raise the intensity of competition, thus gradually eroding the initial temporary monopoly. Given that 
the expectation of a temporary monopoly had induced entry, the gradual increase of the intensity of competition will gradually reduce the inducement to enter and will begin to provide an inducement to exit the population. Firms leaving a particular population will then have an inducement to create further niches in which they will initially enjoy a temporary monopoly. Each population can then be expected to go through a lifecycle beginning with a very low intensity of competition and ending with an intensity of competition at least equal to that of the other pre-existing sectors (Saviotti, 1998b). The situation described here is very similar to the one envisaged by Schumpeter when he used railroadisation as an example of the emergence and decline of industrial sectors (Andersen,1999).

A further contribution to exit in the model comes from mergers and acquisitions. We expect the probability of mergers and acquisitions to increase as the adjustment gap is reduced and the market moves towards saturation. Furthermore, we expect the frequency of mergers and acquisitions to increase the greater are the positive returns to adoption, that include various types of static and dynamic scale economies, learning effects etc.

The previous considerations refer to the dynamics of a population of firms, corresponding to an industrial sector. The model itself is designed to create a sequence of populations with interacting dynamics. However, as it was pointed out above, different population are interacting at least for what concerns the intensity of competition. The intensity of competition in a pre-existing population represents an inducement to exit and to establish a new niche, where the first entrepreneurs would have a temporary monopoly. This niche might subsequently become a fully developed market. Thus the saturation of a pre-existing population would induce the creation of new ones. In fact, the interactions of different populations can be more structured. For example, the extent of inter-population competition can accelerate or slow down the process of saturation of a given population. Moreover, the search activities that can influence the maximum demand in a sector are not only those performed within the population, but they include also externalities or spillovers coming from other populations.

Before proceeding to the technical presentation of our model we need here to summarise some considerations about variety and economic development.

\section{3) VARIETY AND ECONOMIC DEVELOPMENT.}

Testing the importance and role of qualitative change in economic development involves the definition of one or more variables enabling us to represent and to treat analytically qualitative change. One such variable is variety, defined as the number of actors, activities and objects required to describe the economic system. It must be pointed out that in this context variety can be used at a higher level of aggregation than the one traditionally used in much of the economic literature on the subject. While traditionally variety measured the degree of differentiation of a product group, in the present paper it is used to measure the degree of differentiation of economic systems at different level of aggregation starting from a firm or an individual product and ending with the world economy. In this paper then variety is a measure of the extent of differentiation of the economic system.

Two hypotheses link variety to economic development:

Hypothesis 1: The growth in variety is a necessary requirement for long-term economic development. 
Hypothesis 2: Variety growth, leading to new sectors, and productivity growth in pre-existing sectors, are complementary and not independent aspects of economic development.

These two hypotheses can be justified by the imbalance between productivity growth and demand growth (Pasinetti, 1981,1993). If productivity keeps increasing all the time while the demand for new goods and services reaches a saturation point, an imbalance arises. If the economy were constituted by a constant set of activities, in presence of growing productivity it would become possible to produce all demanded goods and services with a decreasing proportion of the resources used as inputs, including labour. This imbalance would then constitute a bottleneck for economic development. The addition of new goods and services to the economic system, that is, a change in composition leading to a growth in variety, can be a form of compensation for the potential displacement of labour and of other resources. Variety growth is then required for the long term continuation of economic development. On the other hand, new goods and services can only be generated by means of search activities. The resources required for these activities can only come from the increases in productivity in preexisting sectors in a way similar to what happened during the process of industrialisation. Then productivity growth in agriculture created the resources required for industrialisation (Kuznets, 1965). Similarly productivity growth in pre-existing sectors creates the resources required for search activities and thus for the generation of new products and services. In a Schumpeterian fashion, the growing productivity of the routines constituting the circular flow creates the resources required for innovation, without which economic development would come to a halt.

The creation of variety is not independent of the nature of competition. For example, the balance between inter- and intra-population competition is a crucial variable determining variety growth. It can be shown that in order for variety to grow intra- population competition must be more intense than inter-population competition (see Saviotti, Mani, 1995; Roughgarden, 1996). This result can be justified either by the myopic behaviour of incumbent firms in existing sectors or by their inability to understand and internalise the new technology. If incumbent firms in a technology $\mathrm{T}_{0}$ do not realise the competitive threat posed by a new technology $\mathrm{T}_{1}$ they continue competing amongst themselves, thus privileging intra-industry competition. If they were to allocate all or a very large percentage of their resources to the new technology $T_{1}$, they would slow down the emergence of $T_{1}$. It can be expected that firms incumbent in $\mathrm{T}_{0}$ will be less able to develop the new technology than entrants in $\mathrm{T}_{1}$, at least in the early phases of $\mathrm{T}_{1}$ life cycle. Interestingly, from hypothesis 1 it follows that the best conditions for economic development do not coincide with the maximum possible intensity of competition: an intensity of inter-industry competition greater than that of intra-industry would lower the rate of creation of variety and thus of economic development.

\section{3) THE MODEL.}

In this model the dynamics of each industrial sector is determined by the balance between the entry and the exit of firms. As previously pointed out, entry is determined by the adjustment gap $A G_{i}$. This is understandable since $A G_{i}$ represents the size of the market demand for a good/service $\mathrm{i}$ that is still unsatisfied. Furthermore, entry is also determined by financial availability $\mathrm{FA}_{\mathrm{i}}$. Financial availability here carries the subscript $\mathrm{i}$ because it is dependent on the features of sector i. For a given availability of financial capital in the economy as a whole, the quantity that is allocated to sector $i$ depends on the size of the sector and on its perceived potential. The latter element is likely to play a greater role in emerging sectors, where there is 
a limited or on existent track record and where, therefore, investment is essentially based on future prospects. Thus $\mathrm{FA}_{\mathrm{i}}$ does not depend only on general financial availability, but also on the ability of economic agents other than the founders of firms to evaluate the prospects of new sectors. In fact, at constant general financial availability, $\mathrm{FA}_{\mathrm{i}}$ is likely to increase as a sector grows and as the knowledge about it becomes more widespread in the economy. $\mathrm{FA}_{\mathrm{i}}$ is likely to depend also on the capacity of an economy to adapt its current institutions to new tasks or to develop completely new institutions. An example of this would be the emergence of venture capital in response to the needs of high technology firms. Summarising, in this model the rate of entry depends on the adjustment gap and on the financial availability.

Exit is determined by the increasing intensity of competition and by mergers and acquisitions. As Schumpeter $(1912,1934)$ pointed out, the first entrepreneur to create a new sector enjoys a temporary monopoly, in part shared by early imitators. However, as imitative entry continues to occur, the intensity of intra- industry competition gradually increases until the temporary monopoly is completely eliminated. As the new and innovating sector looses its special features and becomes another routine of the economic system, the inducement to enter disappears and it is eventually replaced by an inducement to exit. Furthermore, as the sector approaches saturation and in presence of increasing returns to adoption, the rate of mergers and acquisitions contributes to reducing the number of firms in the sector. It can be observed that failure has not been included amongst the mechanisms contributing to exit. While it is clear that firm failure is an exit mechanism, its rate is likely to increase based on the same factors that affect $\mathrm{IC}_{\mathrm{i}}$ ad $\mathrm{MA}_{\mathrm{i}}$. As a consequence, in the interest of simplicity, the rate of failures has not been included in the model. The part of the model discussed so far is related to the analysis of one sector. The interactions between different sectors occur at two levels: first, the increasing intensity of competition as a sector $i$ approaches saturation leads to exit and contributes to the inducements to create niches that will eventually become new markets; second, the intensity of competition includes an inter-industry component, that depends on the degree of substitutability of the outputs of different sectors. Of course, the inducement to leave a pre-existing sector will not lead to the creation of a niche or of a market unless the technological opportunity for the creation of the new sector exists. In other words, economic development will proceed smoothly only if there is co-ordination between the evolution of old sectors and the emergence of new ones. Specifically, since it takes time and other resources to perform the search activities required for new technological opportunities this co-ordination implies that a range of search activities required to prepare new sectors be performed in advance with respect to the emergence of the new sectors. We now pass to the detailed description of the model.

The basic equation gives the rate of growth of firms within a given population:

$$
\frac{d N_{i}}{d t}=k_{1} \cdot F A_{i} \cdot A G_{i}-I C_{i}-M A_{i}
$$

Where $F_{i}$ represents financial availability, $A G_{i}$ the adjustment gap in sector $i, I_{i}$ the intensity of competition in sector $\mathrm{i}$ and $\mathrm{MA}_{\mathrm{i}}$ the rate of mergers and acquisitions in sector $\mathrm{i}$. The definition of the adjustment gap is:

$$
A G_{i}=D_{i, \max }-D_{i}
$$

Maximum demand is determined by the level of search activities: 


$$
D_{i, \max }=S E_{i}^{t}
$$

This means that the population of potential adopters of a given good or service is not fixed, but can change in the course of time. Demand itself is assumed to be equal to total output at all times:

$$
D_{i}^{t}=\left\{N_{i}^{t} \cdot Q_{i}^{t} \text { for } D_{i}^{t-1} \leq D_{\max }^{i} ; D_{\max }^{i} e l s e\right\}
$$

Where $\mathrm{Q}_{\mathrm{i}}^{\mathrm{t}}$ is the average output per firm.

Search activities are expected to grow in the course of time during the life cycle of the sector. We expect them to grow more rapidly at the beginning of the life cycle of the sector and their rate of growth to slow down as it becomes progressively more difficult to exploit the technological opportunities left in the sector. Thus we use for $\mathrm{SE}_{\mathrm{i}}{ }^{\mathrm{t}}$ the following expression:

$$
S E_{i}^{t}=1+k_{4}\left[1-\exp \left(-k_{5} D_{a c c, i}^{t-1}\right)\right]
$$

Where $D_{\text {acc, }}{ }^{t-1}$ is the total accumulated demand in sector $\mathrm{i}$ at time $\mathrm{t}-1$. The presence of accumulated demand corresponds to the learning effects that take place during the life cycle of the sector. The constant $\mathrm{k}_{5}$ measures the rate of learning. The higher the value of $\mathrm{k}_{5}$ the faster $\mathrm{SE}_{\mathrm{i}}^{\mathrm{t}}$ increases for a given level of accumulated demand. On the other hand $\mathrm{k}_{4}$ measures the technological opportunities existing in the sector because for a given rate of learning it determines the scope of a technology and thus the expenditures on search activities corresponding to a given level of demand.

The output of each firm can be expected to increase in the course of time as firms learn and as they exploit the spillovers created by the search activities performed in the sector. The average output per firm is then given by:

$$
Q_{i}^{t}=1+t^{p o p}, i\left[1-\exp \left(-k_{11} \cdot S E_{i}^{t}\right)\right]
$$

Where [1-exp(- $\left.\left.\mathrm{k}_{11} \mathrm{SE}_{\mathrm{i}}^{\mathrm{t}}\right)\right]$ represents the effect of exploiting intensive opportunities and $\mathrm{t}^{\mathrm{pop}, \mathrm{i}}$ the learning effects in time.

The intensity of competition $\mathrm{IC}_{\mathrm{i}}$ in population $\mathrm{i}$, as given by eq (2), is not very practical for our model. First, the density in characteristics space and the distance in service characteristics space are not easy to measure. Second, even if they could be measured they would add to the number of variables present in the model. In order to overcome these difficulties we tried to express $\mathrm{IC}_{\mathrm{i}}$ only in function of the number of firms. The approximate expression that we used for $\mathrm{IC}_{\mathrm{i}}$ is given in equation (9):

$$
I C_{i}^{t}=k_{8} \cdot \frac{N_{i}^{t-1} \cdot N_{t o t}^{t-1}}{k_{6} \cdot N_{i}^{t-1}+k_{7} \cdot N_{\text {tot }}^{t-1}}
$$


Financial availability $\mathrm{FA}_{\mathrm{i}}$, is not simply the amount of money available, but it represents the financial resources that can be invested in sector i. Such resources can be invested if a sufficiently accurate assessment of the probability of success of the Investment can be made. In turn, such assessment requires knowledge of the activities upon which the population or sector is based. In the case of a radically new technology the knowledge is likely to relatively scarce at the beginning of the life cycle of a sector. We can expect this knowledge to increase as the sector develops and thus financial availability to grow as the sectors matures. Thus $\mathrm{FA}_{\mathrm{i}}$ is given by the following expression:

$$
F A_{i}^{t}=k_{3} \cdot C^{t}
$$

Where $C^{t}$ is total financial capital available in the economic system at time $t . k_{3}$ measures the propensity of investors to place capital in sector $\mathrm{i}$ at time t. This propensity is determined both by the potential of technology $i$ and by the ability of economic agents at time $t$ to evaluate such potential. Thus the value of $\mathrm{k}_{3}$ can increase during the life cycle of the sector as more knowledge, allowing to assess more effectively the prospects of the sector, accumulates.

The rate of mergers and acquisitions can be expected to increase with the returns to adoption and with the extent of saturation of the sector. Thus we use the following expression:

$$
M A_{i}^{t}=k_{9} \cdot \frac{N_{i}^{t-1} \cdot M C_{i}^{t-1}}{A G_{i}^{t}}
$$

It is to be noticed that $\mathrm{MC}_{\mathrm{i}}^{\mathrm{t}-1}$, returns to adoption, can include static and dynamic economies of scale, network externalities, learning effects etc.

What has been described so far refers to the dynamics of a particular population. However, the presence of an intra- and of an inter-population term in the intensity of competition links the dynamics of different populations. So the saturation of one population, say i, will induce the creation of a subsequent population, say $i+1$. Furthermore, the intensity of competition within each population will be influenced by other populations. As a consequence, entry conditions for the creation of new sectors will be:

$$
N_{i}^{t}=\left\{0 \text { for } D_{i}^{t} \leq D_{\max , 0}^{i} ; N_{i}^{t} \text { else }\right\}
$$

Important elements required to define the dynamics of new sectors are the time at which such sectors will start developing and the relationship that they will bear to pre-existing sectors. For what concerns the former question, we have assumed that the new sector will start developing only after a pre-existing one has reached saturation, that is after the adjustment gap has fallen to zero. For what concerns the second question this model is unable to define the relative levels of demand of subsequent sectors. To treat effectively this problem we need to combine this model with a model of demand (Saviotti, 2001). We intend to do that in our future research. In this paper we do not differentiate the levels of demand of different sectors, but we explore the effect of a number of factors that can affect differentially the level of demand in all sectors. 


\section{4) RESULTS}

We performed our calculations of the dynamics of interacting firms populations in the following order. First, we picked what seemed reasonable values of the constants $\mathrm{k}_{1}-\mathrm{k}_{11}$ in the equations of the model and we calculated the curves for the main variables of the model, that is the number of firms and its rate of growth, the demand, the adjustment gap, the intensity of competition, the rate of mergers and acquisitions, the average firm output. We called the set of conditions leading to these results the standard scenario. We then performed a number of experiments by varying selectively some of the constants of the model. We describe here the standard scenario and the experiments.

\section{1) THE STANDARD SCENARIO.}

The standard scenario was obtained by giving particular values to the constants $\mathrm{k}_{1}-\mathrm{k}_{11}$. The values of these constants are described in table 1 . We do not have any ways of measuring them in real systems. Thus we tried different sets of values until we obtained results that seemed to simulate a realistic process of the growth of existing sectors and of the emergence of new ones. Once we were satisfied of having obtained this result we called the corresponding set of values of the constants the standard scenario. We then calculated and plotted the results for what concerns the main variables characterising this embryonic economic system. The sets of values used and the results obtained are given here.

\begin{tabular}{|l|l|c|}
\hline Constant & Interpretation & $\begin{array}{c}\text { Value used in the } \\
\text { standard scenario }\end{array}$ \\
\hline $\mathrm{k}_{1}$ & entry conditions & 1 \\
\hline $\mathrm{k}_{3}$ & weight for financial availability & 0.01 \\
\hline $\mathrm{k}_{4}$ & technological opportunities & 50 \\
\hline $\mathrm{k}_{5}$ & learning rate & 0.01 \\
\hline $\mathrm{k}_{6}$ & intraindustry competition & 100 \\
\hline $\mathrm{k}_{7}$ & interindustry competition & 1 \\
\hline $\mathrm{k}_{8}$ & weight for competition & 0.1 \\
\hline $\mathrm{k}_{9}$ & weight for mergers \& acquisitions & 0.00005 \\
\hline $\mathrm{k}_{11}$ & learning curve effect & \\
\hline
\end{tabular}

Table 1: Parameter values of the standard scenario

The calculations were performed for either three or five populations. Of course, this is not a realistic number for any economic system. This is due to the fact that both the first and the last of the sector to emerge are very specific in terms of their interactions. The first sector in our artificial economic system for a while does not interact with any other sector. The last sector is truly artificial because we have 'frozen' the history of our system by eliminating from the last population the inducements to the creation of subsequent ones. Thus an intermediate sector would be the only one to be both preceded and followed by other sectors, as we expect to happen normally in economic development.

The properties of our artificial system that we calculated are shown partly in the text and partly in Appendix 1. In the text, for reasons of brevity, we discuss only a part of these properties. The number of firms within each population increases first and then decreases until it reaches an almost constant level while still falling slowly (Fig. 3). This behaviour is the result of the balance between entry and exit, with entry due to an adjustment gap which is very large at the beginning and gradually decreases, and with exit becoming progressively 
more frequent as the intensity of competition increases and as more mergers and acquisitions reduce the number of firms.

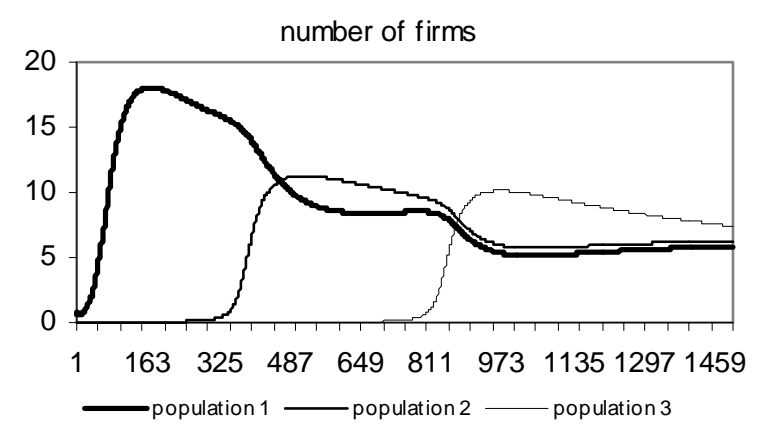

Fig. 3. Number of firms for three populations in the standard scenario.

We can also observe that the number of firms in each population falls more rapidly when a new population is created, as a consequence of increased inter-population competition. We can see that the rate of growth of the number of firms in each population $(\mathrm{dN} / \mathrm{dt})$ increases rapidly at the beginning and then slows down to almost zero, but it falls and becomes negative at the origin of a subsequent population.

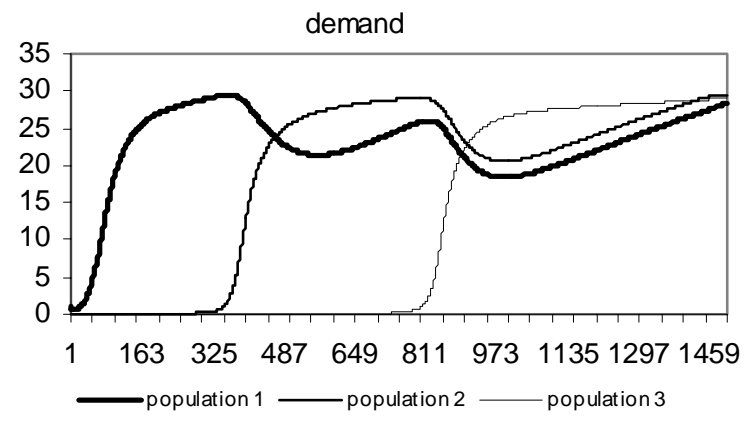

Fig. 4. Variation of sectoral demand in standard scenario.

Demand (Fig. 4) is seen to increase in each population after the initial entries that created the population itself until a relatively stable state is achieved. The phase of rapid initial rise within each population (e.g. population 2) leads to a fall in the demand level for previous populations. In this model there is no explicit representation of income, but we can assume income to be equal to total output. Thus in the short run income is redistributed towards the output of the new sector and the share allocated to old sectors falls. However, subsequently productivity gains in the economy raise the demand for all sectors of the economy. In this paper the maximum value of demand for each sector increases until it attains an almost constant value, which is fixed for all sectors. This is clearly an unrealistic feature, but we propose to modify it in a subsequent version of the model, in which a more explicit representation of the dynamics of demand, as discussed in Saviotti (2001), will be introduced. In the standard scenario we assume $D_{\max }{ }^{i}$ (the maximum demand that can be achieved in sector i) to be equal for all sectors. Considering that we are now starting to explore the broad qualitative features of the model, this assumption is adequate for our present purposes. The adjustment gap rises to a maximum and then falls to a stable state. In a more general sense, we expect $D_{\max }$ i to change, and possibly to increase as a result of the improvements introduced after the emergence of the innovation giving rise to the sector. In turn, such improvements would be the result of search activities. 
The intensity of competition increases gradually as more firms enter, reaches a maximum and then falls gradually to an almost stable state as exit reduces the number of firms (Fig. 5). The creation of each subsequent population raises the intensity of competition in the pre-existing ones, due to increased inter-population competition. As we can see from the evolution of the number of firms (Fig. 3), the natural tendency of each population is to produce a rather concentrated industrial structure. However, this does not lead to a generalised fall in the intensity of competition (I.C.), in the whole economy. This is due to the effect of interpopulation competition. If there were only intra-population competition I.C. would fall to a low and constant value as the number of firms falls and the industrial structure converges to an oligopoly. Such outcome is not obtained because every new sector adds an inter-population component to the I.C. of every other sector. The average level of I.C. is thus kept high by inter-population competition.

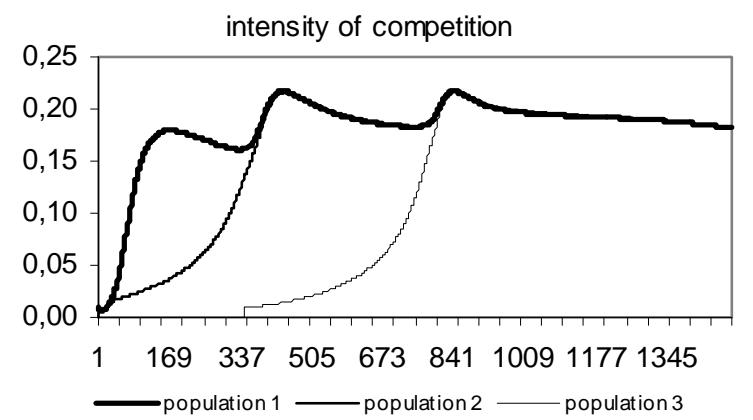

Fig. 5. Variation of the intensity of competition in different sectors.

The output per firm increases gradually as a result of learning effects and the rate of mergers and acquisitions increases at first, though with a lag with respect to the number of firms, and then slows down as the number of firms falls (Fig. A.1).

The basic features of the economic system simulated by this model seem to indicate the existence of an industry life-cycle. This life-cycle is essentially driven by competition. As a new innovation creates an adjustment gap, thus defining the scope of the sector, early entrants find themselves in a situation of temporary monopoly. As imitation induces entry the intensity of competition increases, thus reducing further entry, and eventually stimulating exit. The intensity of competition does not only affect the dynamics of one population, but also of the subsequent ones. The attainment of very intense competition in a population induces the creation of new niches, where the early entrepreneurs will again enjoy a temporary monopoly. The process of economic development simulated in this model involves a set of overlapping and interacting populations/sectors. Let us also observe that the life-cycle predicted by the model is the result of the balance of entry and exit, as determined by the adjustment gap, by the intensity of competition and by mergers and acquisitions, without any reference to either dominant designs (Utterback and Suarez, 1994) or to the balance between product and process innovations (Klepper, Simons, 1997). This implies that any real industry life-cycle can be driven as much by competition as by any of the factors mentioned above.

\section{2) EXPERIMENT $\mathbf{N}^{\circ}$ 1. VARYING TECHNOLOGICAL OPPORTUNITY.}

The constant $\mathrm{k}_{4}$, that appears in eq (7) for search activities $\mathrm{SE}_{\mathrm{i}}^{\mathrm{t}}$, measures the extent of technological opportunity of the technology that created a new sector. In the standard scenario $\mathrm{k}_{4}$ had the same value for the different populations. In this experiment we varied the values of $\mathrm{k}_{4}$ for different populations. We explored the situation in which the technological opportunity 
of each subsequent population is higher than that of the pre-existing one. Although there is no guarantee that such a condition is going to apply systematically to all new emerging sectors, it is also not an implausible one in particular cases. In the past it was considered that agriculture had an intrinsically lower potential for productivity improvement than manufacturing. Electronics and information based sectors seem to manifest a higher rate of productivity growth than historically displayed by mechanical sectors. With these considerations we do not want to prove that the pattern of increasing technological opportunity by subsequent populations of firms is of general applicability, but simply that there are a number of cases in which this could happen. In this part of the paper we are exploring a scenario in which technological opportunity increases for each subsequent population. In the experiment we used two sets of values, corresponding to experiments $1 \mathrm{a}$ and experiment $1 \mathrm{~b}$ respectively (Table 2).

\begin{tabular}{|l|l|}
\hline Table $\mathrm{N}^{\circ} 2$ \\
\hline $\begin{array}{l}\text { Values of the constant } \mathrm{k}_{4} \text { used in experiments 1a and } 1 \mathrm{~b}, \\
\text { and different from those of the standard scenario. }\end{array}$ \\
\hline Experiment 1a & Experiment $1 \mathrm{~b}$ \\
\hline $\mathrm{k}_{4}{ }^{1}=40$ & $\mathrm{k}_{4}{ }^{1}=40$ \\
\hline $\mathrm{k}_{4}{ }^{2}=50$ & $\mathrm{k}_{4}{ }^{2}=60$ \\
\hline $\mathrm{k}_{4}{ }^{3}=60$ & $\mathrm{k}_{4}{ }^{3}=80$ \\
\hline
\end{tabular}

These changes (Fig. 6) lead to an earlier start of the life cycle of populations 2 and 3, to a higher maximum number of firms at the peak of the life cycle, to an increase in the steady state level of demand of each population with respect to the pre-existing ones (Fig. 7) and to an increase of the maximum level of demand of each population with respect to the preexisting ones (Fig.8). These effects are qualitatively the same, but greater in experiment 1b), where the increase in technological opportunity is even greater.
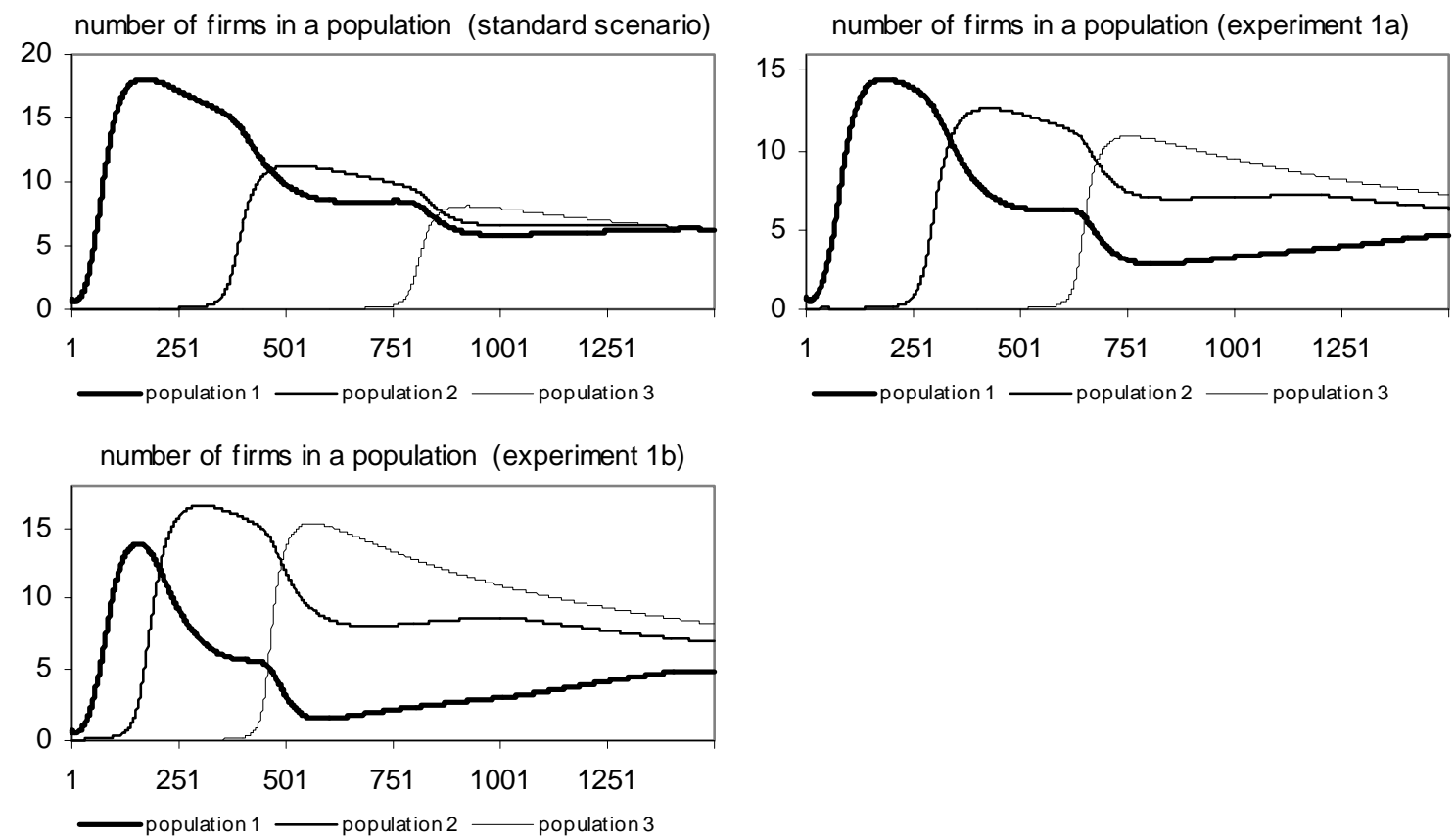

Fig. 6. Influence of technological opportunity on the number of firms. 

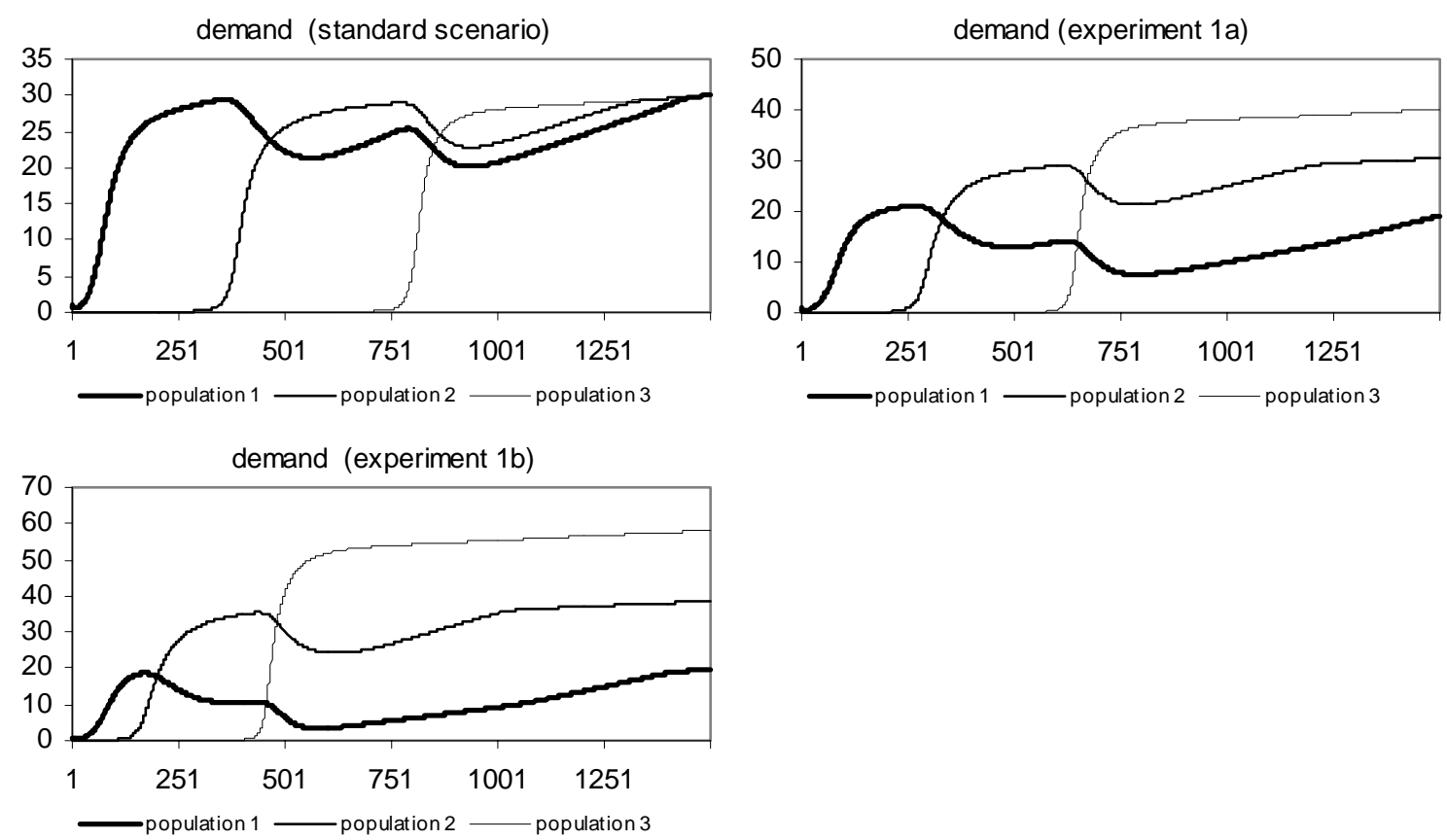

Fig. 7. Influence of technological opportunity on demand
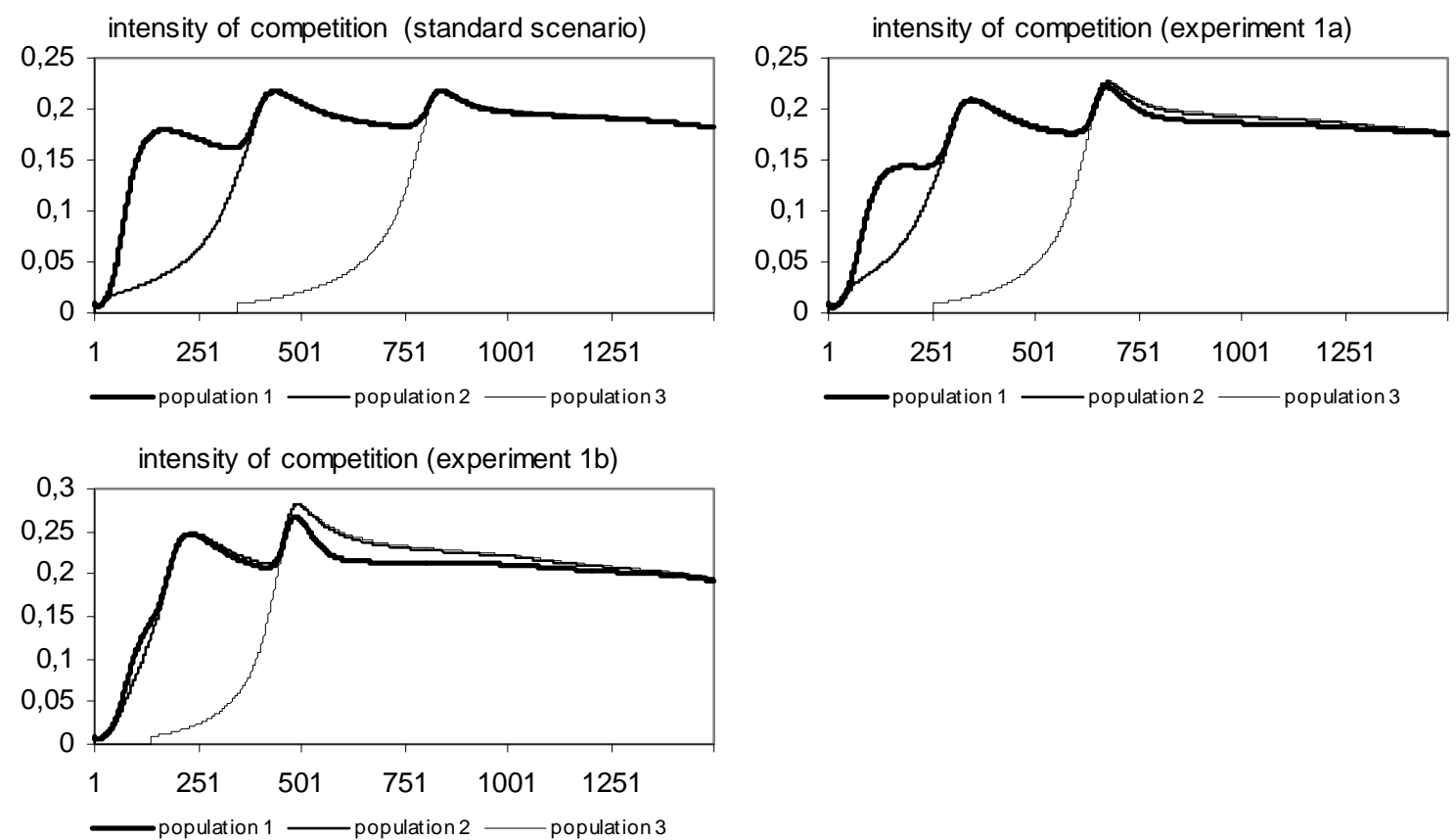

Fig. 8. Influence of technological opportunity on the intensity of competition

Summarising, we could say that the effect of an increase in technological opportunity of each new sector with respect to pre-existing ones, is an acceleration of the process of economic development, determined by a faster emergence of new sectors, and an increase in the scope of economic development, as shown by the increase in the number of firms that each sector can support and by the higher levels of demand eventually achieved in each sector. 


\section{3) EXPERIMENT $N^{\circ} 2$.}

In this experiment we varied the value of the constant $\mathrm{k}_{5}$ for different populations with respect to the standard scenario. $\mathrm{k}_{5}$ takes a higher value for each subsequent population, that is $\mathrm{k}_{5}{ }^{1}<$ $\mathrm{k}_{5}{ }^{2}<. \mathrm{k}_{5}{ }^{3}$. The values used are indicated in Table 3. Given the meaning of $\mathrm{k}_{5}$, this experiment is equivalent to increase firms' rate of learning. Three versions of the experiment are performed.

\begin{tabular}{|l|l|l|}
\hline \begin{tabular}{l} 
Table 3. Values of $\mathrm{k}_{5}$ used in experiment 2 and different \\
from those of the standard scenario. \\
\hline Experiment 2a
\end{tabular} Experiment 2b & Experiment 2c \\
\hline $\mathrm{k}_{5}{ }^{1}=0.005$ & $\mathrm{k}_{5}{ }^{1}=0.005$ & $\mathrm{k}_{5}{ }^{1}=0.005$ \\
\hline $\mathrm{k}_{5}{ }^{2}=0.01$ & $\mathrm{k}_{5}{ }^{2}=0.015$ & $\mathrm{k}_{5}{ }^{2}=0.025$ \\
\hline $\mathrm{k}_{5}{ }^{3}=0.015$ & $\mathrm{k}_{5}{ }^{3}=0.025$ & $\mathrm{k}_{5}{ }^{3}=0.05$ \\
\hline
\end{tabular}

The consequence of increasing firms' rate of learning is to accelerate the emergence of populations 2 and 3 with respect to the standard scenario. This has an equivalent effect of the number of firms and on demand. Entry in population $\mathrm{N}^{\circ} 2$ takes place earlier when the rate of learning for population $\mathrm{N}^{\circ} 2$ increases relative to that of population $\mathrm{N}^{\circ} 1$. The same type of change takes place for population $\mathrm{N}^{\circ} 3$, whose emergence is also accelerated by an increase of its rate of learning relative to that of population $\mathrm{N}^{\circ} 2$ (Fig. 9). Remembering that in our model a population corresponds to an industrial sector, we can see that a faster rate of learning can lead to an earlier emergence of a sector. Contrary to what happened in experiment 1 , in this case only the time path of the number of firms seems to be affected, not its value. The maximum number of firms in each of the three populations remains approximately equal to that of the standard scenario, but it begins to increase earlier for populations $\mathrm{N}^{\circ} 2$ and 3 . 

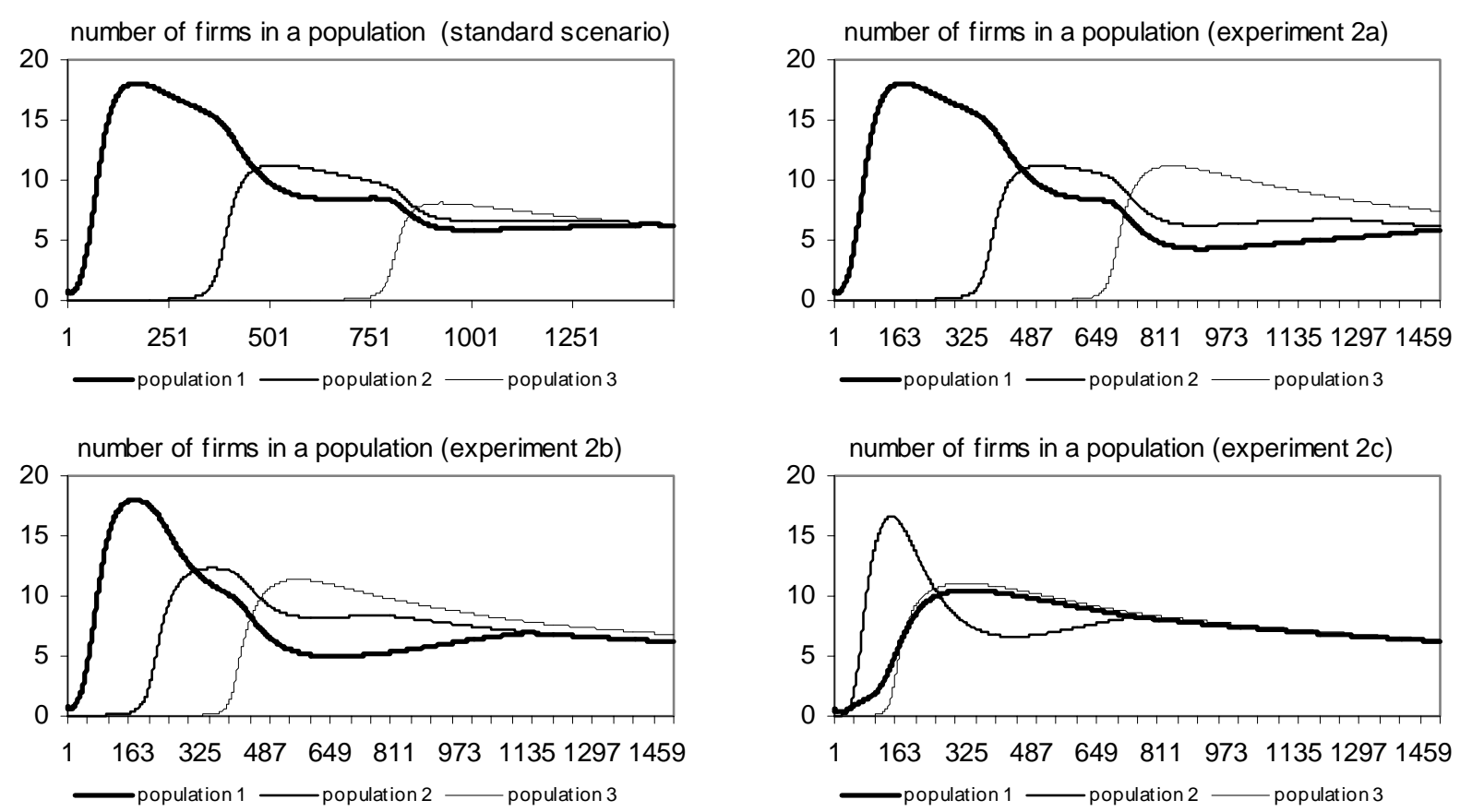

Fig. 9. Influence of the rate of learning on the number of firms

The behaviour of sectoral demand is affected in a similar way (Fig. 10). The demand for each sector output begins to rise more rapidly when we increase the rate of learning, up to the point where the demand for the output of sector $\mathrm{N}^{\circ} 2$ can overtake that of sector $\mathrm{N}^{\circ} 1$. Long run demand for the output of a sector does not seem to be affected by a change in learning rate. This leads us to expect that the aggregate number of firms and the aggregate demand will grow faster the faster the rate of learning. However, in our model a faster rate of learning does not bring joy for everyone. While the system may display a faster growth the number of firms in population 1 begins to fall sooner, due to the inter-sector competition provided by the increased number of firms in populations 2 and 3. If the development of the system can be described by means of the life cycles of different sectors, these life cycles follow a time path that is determined both by the intrinsic features of each sector and by its interactions with other sectors in the economy. We can observe that in the most extreme case considered here (experiment 2c), when the rates of learning of populations 2 and 3 are the highest with respect to population 1, the number of firms and the sectoral demand of population $\mathrm{N}^{\circ} 2$ very soon overtakes those of populations $\mathrm{N}^{\circ} 1$ and 3. 

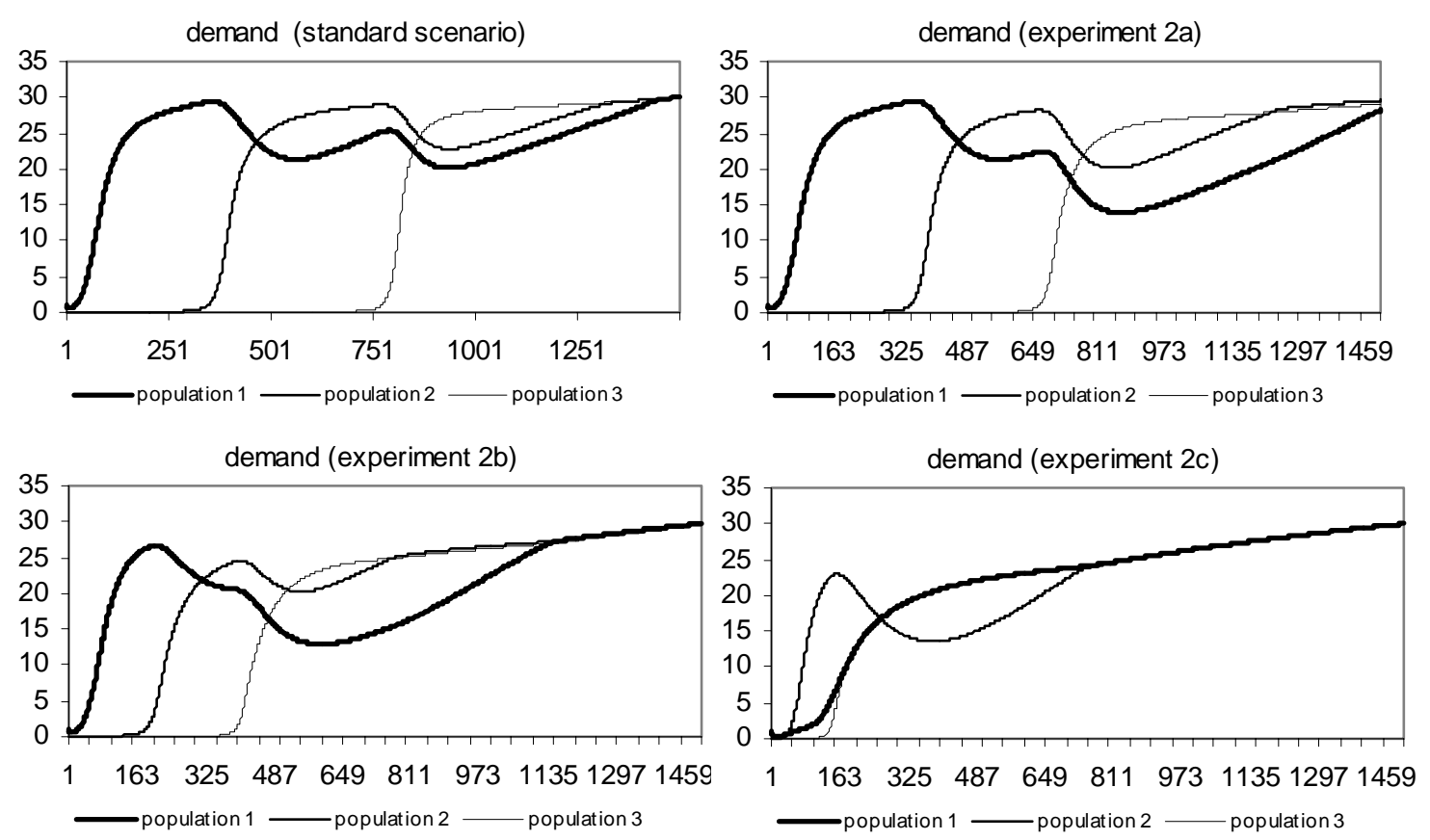

Fig. 10. Influence of the rate of learning on demand

If we compare the results of experiments $\mathrm{N}^{\circ} 1$ and $\mathrm{N}^{\circ} 2$, we can see that the general effect of an increase in technological opportunity (Experiment 1) is both to accelerate the creation of new sectors and to increase their scope, that is, to increase the maximum number of firms in each sector, demand and maximum demand. On the other hand, an increase in the rate of learning of one sector relative to the others only influences the time path of the emergence of new sectors and not their size, as measured either by the number of firms or by demand. Thus technological opportunity is seen as having a greater expansive effect on the development of the whole system than an increase in the rate of learning. However, an increase in the rate of learning can also lead to an overall faster growth for the whole system, but this growth is obtained more by greater efficiency than by an expansion of the markets of the various sectors. In both cases the general improvement of the growth potential of the economic system leads to a collective improvement, but some agents in the system may suffer. Thus an emergence of new sectors may mean faster growth, but it also leads to an earlier and faster emergence of competition for pre-existing (traditional) sectors.

All the analysis so far has been based on individual if interacting populations of firms. The model can also help us to understand the consequences of sectoral dynamics for aggregate growth. The total number of firms and aggregate demand for the whole economy are represented in Fig. 11. 

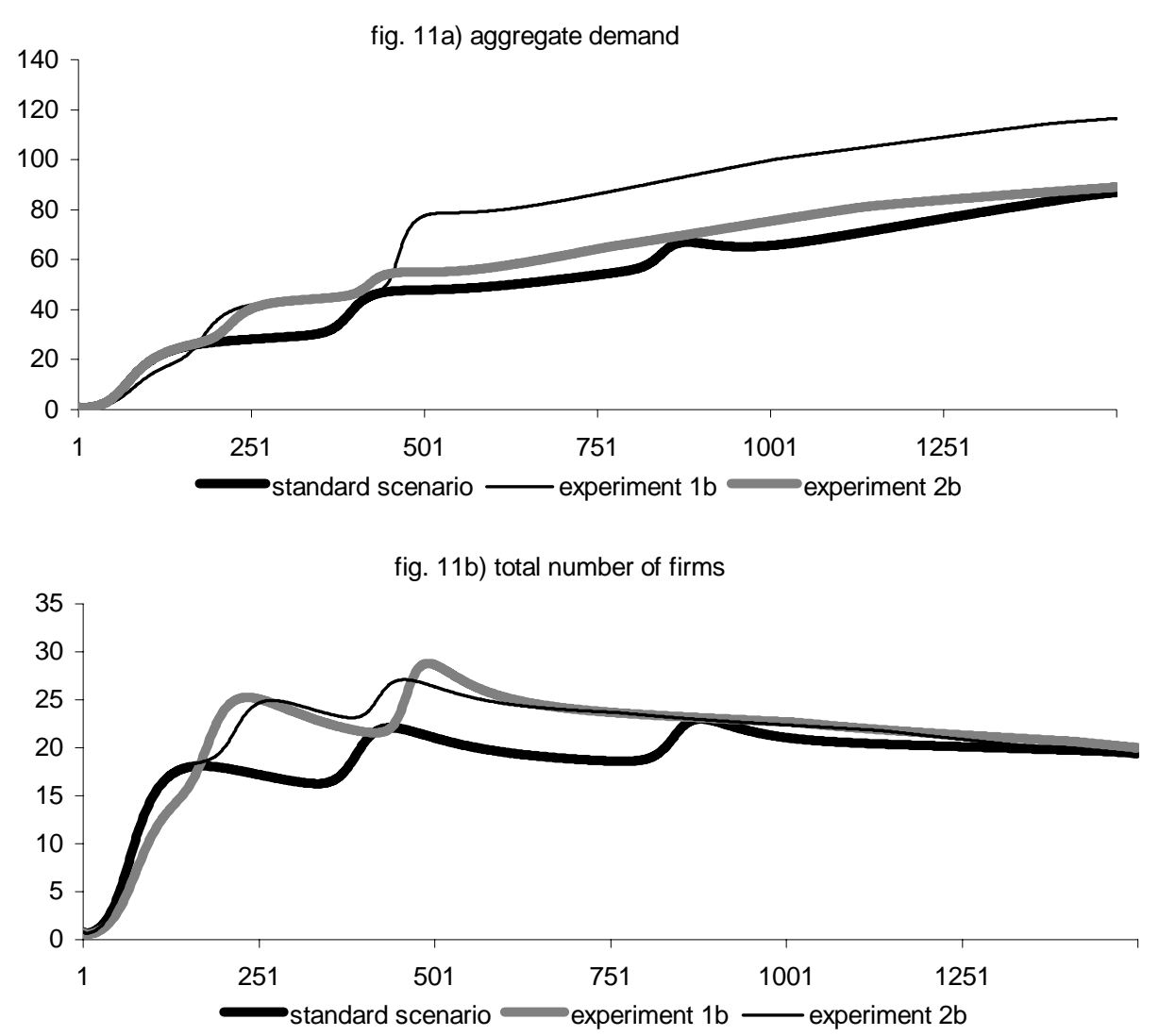

Fig. 11. Aggregate curves with the results of experiments 1 and 2. Fig 11a shows the influence of technological opportunity and of the rate of learning on demand; fig. 11b shows the influence of technological opportunity and of the rate of learning on the number of firms in each sector

Here we can see that aggregate demand is stimulated more by an increase in technological opportunity than by an increase in the rate of learning. The total number of firms grows more rapidly if the technological opportunity or the rate of learning of successive populations are increased with respect to the standard scenario. However, in this case we can see that if the economy were not to generate any more new sectors after sector 3, the number of firms would converge irrespective of the technological opportunity or of the rate of learning. We have to bear in mind that the behaviour of the system after the 'maturity' of sector $\mathrm{N}^{\circ} 3$ is artificial in the sense that we expect new sectors to emerge. The experiment is valuable nevertheless because it tells us that if the emergence of new sectors were to slow down, for example due to the influence of particular economic policies, the overall number of firms in the economy would fall. Increasing intensity of competition, failures, mergers and acquisitions would tend to reduce continuously the number of surviving firms. The total number of firms can only increase or at least remain constant if new sectors are continuously created. Conversely from these results we can expect that in absence of new sectors the system will converge on a set of monopolies, their number being equal to that of the surviving sectors. The same cannot be said about aggregate demand. Here the higher growth path that is established by an increase of either technological opportunity or of the rate of learning persists beyond the maturity of sector $\mathrm{N}^{\circ} 3$. By combining these two results we can expect that the output per firm will continuously increase after the maturity of sector $\mathrm{N}^{\circ} 3$. 


\section{4) EXPERIMENT $\mathbf{N}^{\circ}$ 3. THE EFFICIENCY-VARIETY TRADE-OFF.}

According to $\mathrm{Eq}(8)$ the average output produced by firms in a given sector $\mathrm{i}$ is determined by the level of search activities in the same sector and by a constant $t^{\mathrm{pop}, \mathrm{i}}$, which can be considered a measure of efficiency in the same sector. The constant $t^{\mathrm{pop}, \mathrm{i}}$ can be considered both a measure of efficiency, since at equivalent SE it increases the average firm output in the sector, and a measure of non search-based learning, that is, for example, of learning by doing. In this experiment we varied the value of $t^{\text {pop,i }}$ in order to explore the effect of firm efficiency on economic development. The results we obtained are represented in Fig 12 a) and b), which represent the effect of $\mathrm{t}^{\mathrm{pop}, \mathrm{i}}$ on total demand and on the number of firms.

Fig. 12. Effect of the productive efficiency of firms on the number of firms (12b) and on demand (12a).

fig. 12a) total demand

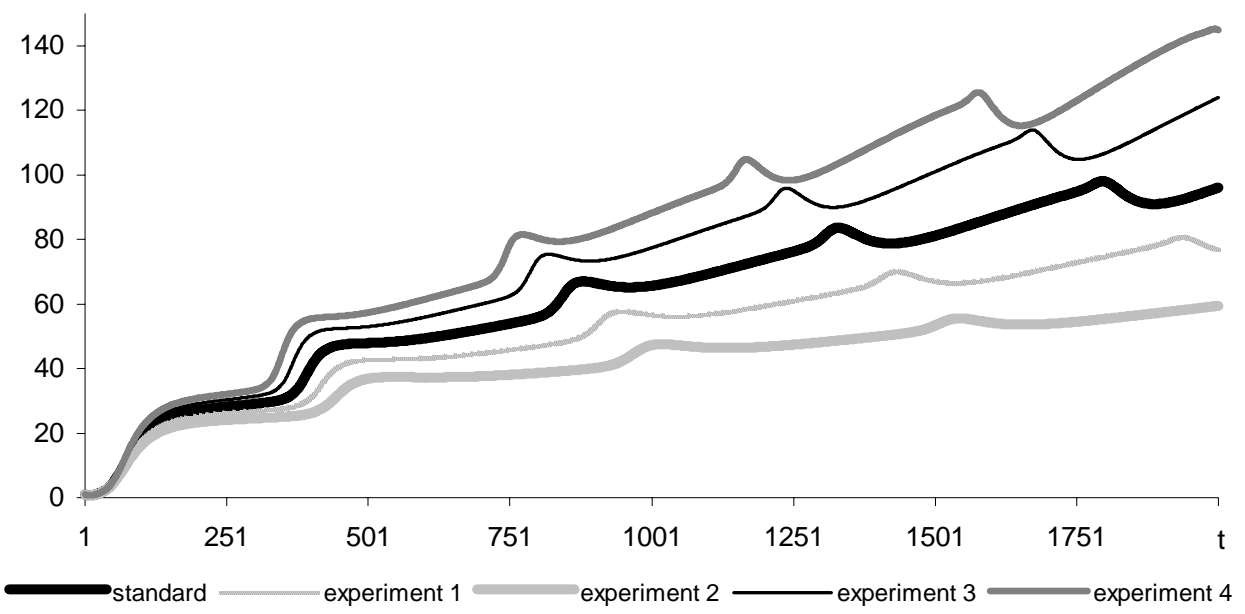

fig. 12b) total number of firms

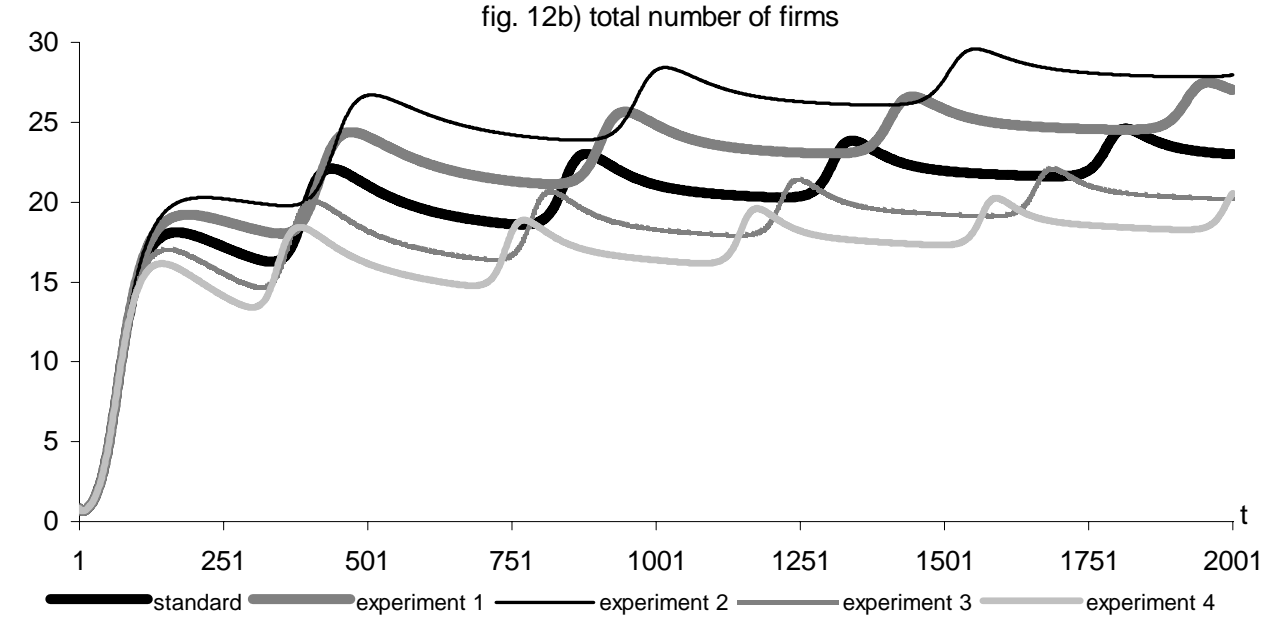

Efficiency increases in experiments 3 and 4 and falls in experiments 1 and 2 . The effect on variety is represented by the number of sectors existing at a given time

The results of this experiment are as follows:

Rate of creation of new sectors. The higher the value of $t^{\mathrm{pop}, \mathrm{i}}$ and thus the higher the efficiency of a sector $i$, the faster the rate of creation of subsequent sectors. If we were to call the time at which each sector first appears $t_{i, 0}$, then $t_{i, 0}$ would be inversely proportional to $t^{\text {pop, } i}$. Thus the effect of generally increasing firms productive efficiency in all the sectors of the economic system would be to accelerate the 'tempo' of economic development. This 
behaviour can be explained by means of the inducement that the saturation of a given sector provides for the creation of subsequent sectors. In turn, this inducement is determined by increasing intensity of competition and by the saturation of demand. On the whole, a higher efficiency in sector i leads to a faster saturation of the same sector, thus triggering the creation of the next one $(i+1)$.

Total demand. The total demand for each sector, and thus for the whole economic system, increases with increasing $\mathrm{t}^{\mathrm{pop}, \mathrm{i}}$. This is due to two reasons: first, since each sector emerges earlier, at any subsequent time the number of sectors in the economic system is greater for a greater value of $t^{\text {pop,i }}$.. Second, the steady state level of demand achieved within each sector increases with $\mathrm{t}^{\text {pop,i }}$. Thus total demand at any time $\mathrm{t}$ will be greater because there are more sectors in the economic system and because each sector has a higher steady state demand.

The number of firms in each sector. The maximum number of firms achieved in each sector at the peak of the life cycle falls with increasing $\mathrm{t}^{\mathrm{pop}, \mathrm{i}}$. The total number of firms in the economic system (Fig. 12a) increases more slowly when the average efficiency of each sector is higher. A faster rise in output, corresponding to a higher intensity of competition, leads to more exit and to more mergers and acquisitions. Thus the maximum number of firms reached in the life cycle of each sector falls with the increasing efficiency of the same sector. Thus the steady state rate of growth in the total number of firms (Fig. 12a) falls with increasing efficiency. In our calculations so far we varied by the same extent the efficiency of all sectors. Of course, this does not need to be the case in a real economic system. In fact we expect efficiency and its rate of growth to vary differentially amongst sectors, thus leading to structural change. This possibility will be explored in subsequent experiments.

The results described above provide a considerable if not definitive confirmation for the hypothesis about the complementarity between variety growth and efficiency growth (Saviotti, 1996). A greater efficiency allows the more rapid creation of new sectors, and leads to a greater net number of sectors in the economic system at a given time, that is to a higher variety.

These results have some interesting implications for economic development. First, if we consider the general development of the world system without focusing on any particular country, we can see that the rate of growth of the economic system increases with the increasing efficiency of each sector. We have to bear in mind at this point that the calculations that we performed so far attribute the same value of $t^{\text {pop,i }}$ to all the sectors. Thus the development we have analysed is a proportional form of development, in which all sectors progress in the same way. Within this framework the saturation of any given existing sector accelerates the rate of creation of subsequent ones. This type of development and structural change takes place because new sectors are continuously (in the long run) added to the economic system. Thus the composition of the system changes and this change in composition drives its rate of growth. A clear relationship exists in our artificial economic system between structural change and changes in the composition of the system on the one hand, and the rate of growth of the system on the other hand. However, as pointed out before, this type of structural change is not the only possible one. As pointed out above, a different efficiency of each sector would add another component to the process of structural change by making some sectors with high values of $\mathrm{t}^{\text {pop,i }}$ grow more rapidly than others. This second component of structural change has not yet been analysed in our experiments. 
A straightforward extension of our model would be to introduce different 'countries' in our economic system. The word country is not to be understood here in its political sense, but as a partition of the economic system that is sufficiently isolated from the rest of it to have persistently different values of the main parameters determining economic growth and development. Again, this further experiment we will undertake subsequently. Yet, even without performing any calculations we can work out some very simple implications for a system with different countries. Clearly, if a country has higher values of $t^{\text {pop,i }}$ than all other countries, it will create new sectors faster than all other countries, the composition of its economic system will change more rapidly and its variety will grow more rapidly than those of the other countries. Thus a greater efficiency would give countries a competitive advantage because it leads to a faster creation of new sectors. A second implication of our model is that the country with a higher efficiency will tend to have a lower number of firms per unit of output in each sector, that is a higher level of industrial concentration. This result bears a considerable similarity to one of the outcomes of Nelson and Winter's model (1982). First, as in their model, in ours market structure evolves endogenously, driven by intensity of competition, by the saturation of demand and by the opportunities afforded by search activities. As pointed out above, firms compete but attempt to reduce the intensity of competition to which they are subject, first by trying to achieve a temporary monopoly in a niche and later by leaving a sector in which the intensity of competition has become 'too' high. The overall competitiveness of the system is preserved by inter-sector competition, which increases with the number of sectors present in the economy. Thus the mechanisms determining the intensity of competition and industrial concentration in our model are somewhat different to those of $\mathrm{N} \& \mathrm{~W}$ but lead similarly to an endogenisation of market structure. In N\&W model the degree of concentration of market structure increases more rapidly if innovation is fast and imitation easy. In our case we have no explicit imitation mechanism, although firm enter new sectors by imitating early entrepreneurs. However, in our model search activities lead to increasing output, but at a declining rate. Thus late entrants will have a reduced scope with respect to early ones. In other words, the time of entry may correspond roughly to the distinction between innovators (early entrants) and imitators (late entrants) in $\mathrm{N} \& \mathrm{~W}$ model. In our model a higher sectoral efficiency leads to a faster shake out and to a more rapid increase in industrial concentration. The similarities between the results of the two models cannot be exaggerated, because they are quite different in their structure and objectives, although they share a basic Schumpeterian logic.

\section{5) SUMMARY AND CONCLUSIONS.}

In this paper we presented the features of a model of economic development driven by the creation of new industrial sectors. Each sector is considered equal to the population of firms producing a differentiated product. The dynamics of each sector is determined by the dynamics of the overlapping populations of firms corresponding to different sectors. The model dynamics is based on entry, as determined by the adjustment gap created by an innovation defining the sector, and by exit, as determined by the increasing intensity of competition and by mergers and acquisitions. The adjustment gap represents the size of the population of potential adopters of a given product that have not yet adopted. Alternatively, the adjustment gap can be considered as the part of a given market that is still empty or unexploited. In turn, the adjustment gap and the rate at which it is closed by the increasing production capabilities of firms, are influenced by the technological opportunities of different sectors and by their rate of learning. The dynamics of the emergence of new sectors depends not only on the creation of new knowledge and innovations, but by the inducements for the generation of new niches emerging within sectors that were once new and innovating, but 
that, due to an increased intensity of competition, become 'saturated' and thus devoid of new opportunities for growth. An increased intensity of competition within one sector, as determined by the entry of imitators, constitutes the inducement to create a niche that could subsequently become a new sector. The results of this model imply that firms try whenever they can to reduce the intensity of competition to which they are subject. The first entrepreneur creating a niche is induced to do it by the expectation of a temporary monopoly. Further on during the sector life cycle the increasing intensity of competition represents a negative inducement for firms to enter (i.e. an inducement to exit). Firm behaviour in this artificial world seems ambiguous: on the one hand firms avoid competition by looking for temporary monopolies and by avoiding intense competition; on the other hand, they imitate successful innovators by entering market niches and sectors and thus raise the intensity of competition. This ambiguity is reflected in the time path of the intensity of competition (I.C.) (Fig. 3). If each sector were to be isolated it would evolve towards an oligopoly with a decreasing intensity of competition. An inter-population component is added to the I.C. of each existing sector every time a new sector is created. While intra-population I.C. tends to fall, inter-population I.C. increases, thus maintaining a high level of I.C. in the whole economy. Furthermore, mergers and acquisitions reduce the number of firms to an extent depending on the rates of return prevailing in the sector and on its degree of saturation. The dynamics of development of each sector thus depends both on factors internal to the sector itself and by the interactions with other sectors of the economy.

In this model competition for the firms in a sector does not come only from within the sector (Intra-population or intra-sector) but also from other sectors (inter-population or inter-sector competition). The model leads to the emergence of a life cycle for each population/sector. The cycle in this case can be considered a competition life cycle (Saviotti, 1998) since it is started by the temporary monopoly existing in the early stages and ended by the by the increasing intensity of competition in the maturity phase. The model thus has a very strong Schumpeterian flavour.

This model can be considered a very simplified and stylised representation of how economic development is created by qualitative change, leading to a changing composition of the system. Given its simplicity, it already provides some very interesting analysis of the effect of changing composition on economic development. A very large number of experiments can be performed on the model to vary the relative values of the constants contained in it. We started performing some of these experiments, that gave us valuable information on the basic behaviour of the model. Of course, these experiments do not exhaust the scope for exploration of the model and there are other variables whose influence ought to be analysed. We propose to do this in further papers.

The basic behaviour of the model can be described by the dynamics of the following variables:

- number of firms,

- maximum demand

- demand

- intensity of competition

- adjustment gap

- mergers and acquisitions 
The stylised results of the basic scenario show a number of firms that first increases and then falls, a maximum sectoral demand that increases up to a constant value, a sectoral demand that increases up to a maximum, falls and then follows a gradually increasing path in the long term, a rate of mergers and acquisitions that first rises and then falls. On the whole the behaviour can be described as a life cycle driven by competition. Entry is essentially determined by an innovation defining the sector, while exit is due to the increasing intensity of competition and by mergers and acquisitions.

In our experiments we analysed the effect of increasing technological opportunity in newer sectors and of increasing the rate of learning in newer sectors. An increase in technological opportunity for newer sectors with respect to older ones accelerates the emergence of new sectors and expands their scope, that is it raises the maximum number of firms, the maximum demand and demand. An increase in the rate of learning accelerates the emergence of new sectors, but it does not have an expansive effect comparable to that of increasing technological opportunity. A higher rate of learning for one or more sectors accelerates their emergence with respect to that of slower learning sectors. The results of these experiments also show that the effect of changing either technological opportunity or the rate of learning for one or more sectors relative to others is not limited to the sector itself, but it influences other sectors in which these variables are not changing. For example, an increase in the technological opportunity of one sector accelerates its emergence, that is the earliest time of entry of firms into it, but it also accelerates the rate of fall in the number of firms in a preexisting sector that was already near saturation.

An aggregate view of this artificial economic system is obtained by computing the total number of firms in all sectors and total demand. As expected, both an increase in technological opportunity and in the rate of learning lead to an increase in the growth of the aggregate demand for the whole system. The total number of firms in the system is affected in a similar way by an increase in technological opportunity or in the rate of learning: it increases more rapidly and reaches a higher value at the peak of the life cycle. The long run behaviour of the number of firms can be different: in absence of emergence of new sectors the total number of firms converges irrespective of the values of technological opportunity or of the rate of learning. Even if we have to remember that the non-emergence of other sectors after sector $\mathrm{N}^{\circ} 3$ or $\mathrm{N}^{\circ} 5$ is an artificial characteristic of this set of calculations the result shows that the total number of firms in the economic system can only increase if new sectors keep emerging at an adequate rate. If no new sectors were to emerge we could expect the system to converge to a set of sectoral oligopolies.

In another experiment we explored the effect of increasing firm efficiency on the development of the system. As average firm efficiency rises for all sectors, the rate of creation of new sectors increases. Each new sector is created at an earlier time. The development of the system is speeded up. Total demand in each sector reaches a higher steady state value. Correspondingly, the number of firms at the peak in the sector falls with increasing efficiency, leading to a more concentrated market structure in presence of a higher productive efficiency. These results provide considerable, even if not definitive, confirmation for the hypothesis about the complementarity between efficiency growth and variety growth in economic development. By increasing efficiency in each sector, the rate of creation of new sectors, and thus of variety creation in the whole economy, will grow.

In summary, the model that we present in this paper is a dynamic model of growth involving qualitative change. Furthermore, it is a model of growth in which the aggregate output of the 
sector can be calculated by means of the outputs of individual units (firms or sectors). Of course, the model in its present form is highly stylised. A number of modifications are required in order to make it more realistic. For example, the maximum demand is either constant for all sectors, as in the standard scenario, or it increases depending on the technological opportunity of the sector, as in experiment 1 . Both cases are not very realistic. The use of a model of demand that can help us to foresee the relative values of the maximum demand for different sectors is required to overcome this problem (see for example Saviotti, 2001). We plan to do this in further developments of the model. In a sense the present model provides the basic framework for the analysis of the role of qualitative change in economic development. The combination of this framework with other equations providing a better specification of particular phenomena or variables can allow us to improve its realism for what concerns specific aspects (e.g. demand, firm strategy, employment etc.).

\section{REFERENCES}

Aghion P., Howitt P.(1998), Endogenous Growth Theory, Cambridge, Mass, The MIT Press.

Andersen, E.S., (1999), 'Railroadization as Schumpeter's standard example of capitalist evolution: an evolutionary-ecological interpretation', paper presented at the workshop on the History of Evolutionary Thought in Economics, Max Planck Institute for Economic Research, Evolutionary Economics Unit, Jena, 26-28 August 1999.

Cornwall (1977) Modern Capitalism: its Growth and Transformation, London, Martin Robertson.

Fagerberg J.(2000), Technological progress, structural change and productivity growth: a comparative study, Working paper $\mathrm{N}^{\circ} 5 / 2000$, Centre for Technology, Innovation and Culture, University of Oslo.

Fagerberg J., and Verspagen B. (1999), Productivity, R\&D spillovers and trade, Working Paper $N^{\circ} 3 / 1999$, Centre for Technology, Innovation and Culture, University of Oslo.

Hayek F.A. (1978) Competition as a discovery procedure, in New Studies in Philosophy, Politics, Economics and the History of Ideas, London, Routledge.

Klepper S., Symons K.L., Technological extinctions of industrial firms: an enquiry into their nature and causes, Industrial and Corporate Change, Vol. 6 (1997) pp. 379-460.

Kuznets S. , Economic Growth and Structure, New York, Norton (1965)

Maynard Smith J. (1974) Models in Ecology, Cambridge, Cambridge University Press.

Metcalfe (1981) Impulse and diffusion in the study of technological change, Futures, Vol. 13, pp.

Nelson R.R., Winter S.G., (1982) An Evolutionary Theory of Economic Change, Cambridge MA, Harvard University Press.

Pasinetti L.L. (1981). Structural Change and Economic Growth, Cambridge: Cambridge University Press.

Pasinetti L.L., (1993), Structural Economic Dynamics, Cambridge, Cambridge University Press, .

Roughgarden J., Theory of Population Genetics and Evolutionary Ecology. An Introduction, Upper Saddle River, Prentice Hall (1996).

Salter W.E.G., (1960), Productivity and Technical Change, Cambridge: Cambridge University Press

Saviotti P. P., Technological Evolution, Variety and the Economy, Aldershot, Edward Elgar, (1996) 
Saviotti P.P., (2001) Variety, growth and demand, Journal of Evolutionary economics, Vol.11, pp. 119-142.

Saviotti P.P., On the dynamics of approriability, of tacit and codified knowledge, Research Policy, Vol. 26 (1998) 843-56. (*)

Saviotti P.P., Krafft J, (2002) Towards a generalised definition of competition, presented at the meeting of the ETE network held at the Max Planck Institute for Research into Economic Systems, Jena, 28 February $1^{\text {st }}$ Match 2002.

Saviotti P. P. Mani, G.S., Competition, variety and technological evolution: a replicator dynamics model, Journal of Evolutionary Economics, Vol. (1995).

Saviotti, P. P., J. S. Metcalfe, A Theoretical Approach to the Construction of Technological Output Indicators, Research Policy, Vol. 13 (1984) 141-151.

Utterback J.M., Suarez F.F., Innovation, competition and industry structure, Research Policy, Vol 22, (1993) pp. 1-21. 